\title{
Review
}

Kidney Dis

DOI: $10.1159 / 000486829$
Received: October 2,2017

Accepted after revision: January 15, 2018

Published online: February 14, 2018

\section{An Overview on Renoprotective Effects of Thymoquinone}

\author{
Hanieh Shaterzadeh-Yazdi ${ }^{a}$ b Mohammad-Foad Noorbakhsh ${ }^{c}$ \\ Saeed Samarghandian ${ }^{d}$ Tahereh Farkhondeh $^{\mathrm{e}}$ \\ ${ }^{a}$ Research Center of Pardis Hospital, Mashhad, Iran; ${ }^{b}$ Nastaran Center for Cancer Prevention, Mashhad, Iran; \\ 'Division of Pharmacology and Toxicology, Department of Basic Sciences, School of Veterinary Medicine, Shiraz \\ University, Shiraz, Iran; d Department of Basic Medical Sciences, Neyshabur University of Medical Sciences, \\ Neyshabur, Iran; ${ }^{e}$ Cardiovascular Diseases Research Center, Birjand University of Medical Sciences, Birjand, Iran
}

\section{Keywords}

Kidney $\cdot$ Inflammation · Oxidative stress $\cdot$ Renoprotective effects · Thymoquinone

\begin{abstract}
Background: Kidneys as vital organs remove waste material from blood. Additionally, they may also have a role in the electrolyte balance, regulation of blood pressure, and red blood cell genesis. Kidney diseases may be caused by several factors such as ischemia/reperfusion injury, diabetes, and nephrotoxic agents. Oxidative stress and inflammation are involved in the pathogenesis and progression of kidney diseases. Traditionally, natural antioxidants are used for treatment of renal failure in various countries. Summary: People usually select natural antioxidants since they have an opinion that herbal medicine has not any important side effects. Nigella sativa is a flavoring herb that is widely used as a condiment and as a remedy for many disorders. Thymoquinone (TQ), the most important component of black seeds, mainly oil, is considered as an active agent responsible for a lot of the seed's useful effects. This review describes the protective roles and related mechanisms of TQ against renal disorders. The search terms, including $\mathrm{TQ}$, antioxidant, renal
\end{abstract}

ischemia-reperfusion, diabetic nephropathy, and nephrotoxic agent were searched in scientific databases. TQ showed anti-inflammatory and antioxidant properties in animal and in vitro models of several renal diseases caused by inflammation and oxidative stress. Key Messages: Experimental studies have shown beneficial effects of TQ against renal diseases; however, well-designed clinical trials in humans are required to confirm these effects.

(c) 2018 S. Karger AG, Basel

\section{Background}

Nigella sativa, generally known as black seed or black cumin, is an annual flowering bush plant from the family Ranunculaceae which is growing in Southwest Asia, North Africa, and southern Europe [1,2]. The main compounds that have been isolated from $N$. sativa seed include proteins, carbohydrates, fixed oils, essential oil, crude fiber, alkaloids, minerals, vitamins, ash, and moisture. The other components are tannins, resin, saponin, carotene, glucosides, and sterols [3]. One of the major components of the essential oil is thymoquinone (TQ) [4, 5]. Based on the use of $N$. sativa in traditional medicine

\section{KARGER}

(c) 2018 S. Karger AG, Basel

E-Mail karger@karger.com

www.karger.com/kdd
Saeed Samarghandian

Department of Basic Medical Sciences, Neyshabur University of Medical Sciences Razi Street

Neyshabur 9318614139 (Iran)

E-Mail samarghandians@ mums.ac.ir 
as a natural treatment for some diseases, researchers have investigated its protective effects against asthma [6], hypertension [7], diabetes [8], and inflammation [9]. In addition, TQ is known to have antioxidant [10], analgesic, antipyretic [11], antischistosomal [12], antifungal [13], antibacterial [14], anticancer [15], anticonvulsant [16], hepatoprotective [17], and neuroprotective activities [18]. It has been found that TQ has beneficial protective effects against renal diseases through anti-inflammatory, antioxidant, and antiapoptotic activities [19]. The present review aimed to review the recent studies from 2007 to 2017 that describe the protective effects of TQ in the management of kidney diseases.

\section{Evidence Acquisition}

Online literature resources were checked using different search engines such as Medline, PubMed, Scopus, and Google Scholar from 2000 to 2017 to identify articles, editorials, and reviews about renoprotective effects of TQ. In this review article, the words TQ, antioxidant, renal ischemia-reperfusion, diabetic nephropathy, and nephrotoxic agents were applied to search the literature from scientific databases.

\section{Results}

\section{Antioxidant and Anti-Inflammatory Effects of TQ}

Reactive oxygen species (ROS) have been described as an important cause of renal disorders [20-23]. Reducing ROS improves graft maintenance and removal of acute inflammation. The scavenging function of free radicals is a property of black seeds which can prevent lipid peroxidation (LPO). The studies showed that TQ, a major constituent of $N$. sativa seeds, has strong antioxidant, antiinflammatory, and cytoprotective abilities [24-28]. In this regard, Khattab and Nagi [29] studied the protective effect of TQ in the rats with hypertension induced by 4 weeks' administration of $\mathrm{N}$ (omega)-nitro-l-arginine methyl esters (l-NAME) (50 mg/kg/day p.o.). TQ treatment $(0.5$ and $1 \mathrm{mg} / \mathrm{kg} /$ day p.o.) decreased the increase in systolic blood pressure induced by l-NAME. Treatment of the rats with TQ brought increased creatinine $(\mathrm{Cr})$ and glutathione (GSH) to normal levels. TQ prevented the production of superoxide radical in enzymatic and nonenzymatic systems. This study supported the effects of TQ in the rats against l-NAME-induced hypertension and kidney injury through its antioxidant activity [29]. The inhibitory effects of TQ $(100,200,300,400,500,750$, $1,000 \mathrm{nM}$ ) on activation of interleukin-6 (IL-6) and re- dox-sensitive transcription factor nuclear factor kappa B $(\mathrm{NF}-\kappa \mathrm{B})$ were investigated in vitro. An important reduction of advanced glycation end products induced high expression of IL- 6 and NF- $\mathrm{kB}$ in the human proximal tubular epithelial cells. This result showed antioxidative properties of TQ [30].

Ozer et al. [31] investigated the protective effects of TQ on survival, vascular reactivity, mesenteric artery blood flow, oxidative, and inflammatory responses in rats subjected to cecal ligation and puncture (CLP). Intraperitoneal injection (i.p.) of TQ ( $1 \mathrm{mg} / \mathrm{kg} /$ day) for 3 days partially reduced aortic dysfunction and improved mesenteric hypoperfusion induced by CLP. TQ also prevented the increase in the serum levels of alanine aminotransferase, aspartate aminotransferase, blood urea nitrogen (BUN), lactate dehydrogenase, $\mathrm{Cr}$, and inflammatory cytokines (IL-1 $\beta$, IL- 6 and TNF- $\alpha$ ) in the CLP group. The reduction of the GSH levels in spleen, liver, and kidney and the elevation of the malondialdehyde (MDA) levels in kidney, liver, lung, and spleen induced by CLP were prevented by TQ. Additionally, TQ showed the histopathological protective effects on multiple organ injury induced by CLP [31]. Another study supported the ameliorative effects of TQ in renal disorder caused by rheumatoid arthritis in rats. In this study, TQ $(2 \mathrm{mg} / \mathrm{kg}$ dissolved in distilled water, i.p.) and methotrexate (MTX) $(0.5 \mathrm{mg} / \mathrm{kg}$, i.p.) importantly decreased the total clinical score of inflammation and leukocyte numbers, and ameliorated serum $\mathrm{Cr}$ and blood urea [32]. Hosseinian et al. [33] investigated the effects of TQ and renin-angiotensin system blockade on the renal expression of angiotensin II and renal tissue injury after unilateral ureteral obstruction (UUO) in rats. TQ $(10 \mathrm{mg} / \mathrm{kg}$, i.p.) 3 days before UUO and 2 weeks postoperatively importantly ameliorated apoptosis, TNF- $\alpha$ expression, and oxidative damage, but significantly reduced the upregulation of monocyte chemoattractant protein (MCP-1) and angiotensin II compared with the UUO group. This study showed the ability of TQ to improve UUO-induced renal tissue injury, which was comparable to the well-known renin-angiotensin system inhibitors such as losartan and captopril [33].

\section{Ischemia/Reperfusion Injury}

Renal ischemia-reperfusion (I/R) is known as a wellcharacterized model of acute renal injury that leads to both local and far organ damage [34-37]. Various studies have shown that TQ has protective effects against I/R injury to the several organs such as kidneys, lungs, and liver in different experimental models $[38,39]$. The effect of 
TQ on hepatic and renal changes induced by renal I/R in the rats was investigated. In this study, administration of TQ (10 mg/kg, p.o.) before I/R injury led to the reversal of increased MDA content and decreased activity of superoxide dismutase (SOD) and glutathione-S-transferase (GST) in renal and hepatic tissues. Additionally, it decreased the raised alanine aminotransferase and $\mathrm{Cr}$ serum levels and induced CYP3A1 mRNA expression by I/R. TQ also decreased spermidine/spermine N-1-acetyltransferase mRNA expression as a catabolic enzyme that participates in polyamine metabolism in the liver and kidney which was induced by I/R [40]. A study was done to investigate the effect of TQ on the changes in parameters of kidney function after the warm renal I/R injury (I/RI) in rats. Oral consumption of TQ (10 mg/kg/day) 4 days prior to the I/RI for 6 days improved the I/RI effects on the tubular renal functional and hemodynamic parameters as well as the expression of some renal damage markers, profibrotic and proinflammatory cytokines, which showed TQ has renoprotective effects on I/RI-induced renal disorders [39].

\section{Diabetic Nephropathy}

Diabetic nephropathy is the main reason of morbidity and death in diabetic people. To inhibit the expansion of this disease and to ameliorate progressed renal damage, effective remedies are needed [41-43]. Streptozotocin (STZ) is an antibiotic extensively applied in experimental models as an agent capable of inducing type 1 diabetes mellitus, which is known as insulin-dependent diabetes mellitus [44-46]. Studies show that Nigella sativa oil (NSO) and its main bioactive element TQ have, antihyperglycemic, antioxidant, and renoprotective properties in STZ-induced diabetes in the animal models $[47,48]$. The study was done by Sayed [49], which showed that TQ reduced NF- $\kappa$ B activation induced by angiotensin II in a dose-dependent manner, with the maximum inhibitory effect of $500 \mathrm{nM}$. In addition, preincubation of the proximal tubular epithelial cells with TQ caused the disappearance of the second peak of NF$\kappa \mathrm{B}$. The results demonstrated the therapeutic effect of TQ which can be administered to delay end-stage kidney disorders in diabetics. The study performed by Kanter [50] showed that the treatment with TQ ( $50 \mathrm{mg} / \mathrm{kg}$ body weight) by oral gavage in diabetic rats for 12 weeks decreased the capsular thickening, glomerular size, the tubular and glomerular basement membranes, the elevated content of mesangial matrix, and tubular dilatation and renal function as compared with the untreated diabetic rats. The findings showed that TQ treatment leads to the renal structural and functional progress in rats with STZ-induced diabetes. The study was carried out to investigate the feasible beneficial effects of proanthocyanidin (PA), TQ, and their combination to ameliorate the diabetic nephropathy in rats. Treatment of rats with PA $(250 \mathrm{mg} / \mathrm{kg})$, TQ $(50 \mathrm{mg} / \mathrm{kg})$, or PA + TQ $(250+50$ $\mathrm{mg} / \mathrm{kg}$, respectively) orally for 12 weeks showed a decrease in body weight, in addition to reduced SOD and GSH contents. The increased levels of nitric oxide (NO), urea, Cr, IL-6, and MDA were significantly decreased as a result of the treatment. The results indicated that PA and TQ treatment could be introduced as therapeutic protective agents in diabetes through reducing oxidative stress and ameliorating diabetic nephropathy. Therefore, TQ and PA may be clinically effective for supporting the diabetic kidney against oxidative stress [51]. Another study was done to investigate the effects of TQ in the rats with STZ-induced diabetes and to define the predictive cost of epithelial and mesenchymal markers in TQ treatment in rats with diabetic nephropathy. Treatment with TQ $(50 \mathrm{mg} / \mathrm{kg}$, orally) importantly ameliorated renal structural changes in both renal tubules and glomeruli and also the immunohistochemical expression of MMP-17 and mesenchymal markers Fsp1, desmin, and epithelial marker ZO-1 disappearance in the glomeruli of STZ-induced diabetic rats. These findings showed that both epithelial and mesenchymal markers act as good predictors of early renal injury and indexes of TQ reactivity in STZ-induced diabetic nephropathy [52]. A study was designed by Al-Trad et al. [53] to assess the effect of NSO and TQ treatment on podocyte injury, albuminuria, and the complex systems adjusting the extracellular angiogenesis and matrix protein accumulation in rats with STZ-induced diabetic nephropathy. The results indicated that treatment with $2 \mathrm{~mL} / \mathrm{kg}$ NSO or 50 $\mathrm{mg} / \mathrm{kg}$ TQ by oral consumption for 10 weeks importantly ameliorated increased albuminuria and the kidney weight/body weight ratio in STZ-induced diabetic nephropathy. The real-time PCR displayed that the treatment with NSO and TQ inhibited diabetes-induced mRNA overexpression of transforming growth factor- $\beta 1$ (TGF- $\beta 1$ ), vascular endothelial growth factor-A (VEGFA) and collagen IV as well as down-regulation of mRNA expression of the podocyte-specific marker (podocin) in the diabetic kidney. NSO and TQ treatment reduced albuminuria in the diabetic nephropathy experimental models through the preservation of the podocyte function with the suppression of increased extracellular matrix gene expression by preventing TGF- $\beta 1$ production and angiogenesis [53]. 


\section{Nephrotoxic Agents}

It is well defined that many drugs, such as the chemotherapeutic drug (cisplatin) and aminoglycoside antibiotics are able to cause nephrotoxicity [54-56].

\section{Chemotherapy Drugs}

Most chemotherapeutic drugs can lead to nephrotoxicity $[57,58]$. Hence, recent strategies have been focused on preventing chemotherapy-induced nephrotoxicity. $N$. sativa or its isolated constituent TQ are introduced as the potential agent in fighting chemotherapy-induced nephrotoxicity [59].

\section{Doxorubicin}

The study carried out by Elsherbiny and El-Sherbiny [60] showed that oral consumption of TQ $(50 \mathrm{mg} / \mathrm{kg} /$ day $)$ for 3 weeks in rats that received doxorubicin (DOX) as a chemotherapeutic drug, reversed the increased levels of serum $\mathrm{Cr}$, urea, and urinary albumin excretion, whereas animals that received DOX without TQ showed DOXinduced nephrotoxicity. Additionally, TQ ameliorated increased MDA and LPO, and also, it increased the decreased activities of SOD and GST in rats with DOX-induced nephrotoxicity. TQ also decreased the increased renal levels of IL-6, TNF- $\alpha$, and NADPH oxidase 4, and increased the decrease in nuclear factor erythroid 2-related factor 2 (Nrf2) mRNA levels, interleukin-10 (IL-10) levels, and nuclear binding activity. Renal histopathological changes induced by DOX improved with TQ [60].

\section{Cisplatin and Diesel Exhaust Particles}

Ali et al. [61] studied the interaction between cisplatin (CP) nephrotoxicity and a single exposure to diesel exhaust particles and the concurrent treatment with TQ $(20 \mathrm{mg} / \mathrm{kg}$, orally) in rats. The results showed that several biochemical, physiological, and histopathological alterations contained decreased growth and $\mathrm{Cr}$ clearance and increased IL-6, plasma neutrophil gelatinase-associated lipocalin, C-reactive protein, urea and $\mathrm{Cr}$ concentrations, and urinary $\mathrm{N}$-acetyl-b-D-glucosaminidase (NAG) activities induced by $\mathrm{CP}$, and were significantly abrogated by TQ. Also, TQ significantly resolved potentiated indices of oxidative injuries in the kidney tissues, and induced renal tubular necrosis induced by $\mathrm{CP}$ and diesel exhaust particles [61].

\section{Morphine}

A study was designed by Jalili et al. [62] to investigate protective effects of TQ against morphine-induced renal toxicity in mice. The results showed that intraperitoneal administration of TQ $(4.5,9$, and $18 \mathrm{mg} / \mathrm{kg})$ and TQ with morphine importantly increased kidney weight, number, and mean diameter of the glomeruli. Additionally, TQ led to a decrease in BUN, serum NO and serum Cr levels in the groups treated with it compared to the morphine group. This study explained that the renoprotective effects of TQ against damage due to morphine toxicity may be related to its antioxidant and antiapoptotic effects [62].

\section{Gentamicin}

Sayed-Ahmed and Nagi [63] showed that TQ supplementation $(50 \mathrm{mg} / \mathrm{L}$ in drinking water) in rat caused a complete reversal of the gentamicin (GM)-induced increase in BUN, Cr, thiobarbituric acid-reactive substances and total nitrate/nitrite and reduction in GSH, glutathione peroxidase (GPx), catalase (CAT), and ATP to control values. Furthermore, histopathological examination of renal tissues corroborated the biochemical data, wherein TQ supplementation protected kidney against GM-induced degenerative changes. The results of this study proposed that TQ is useful in preventing from the development of GM-induced acute renal failure by a mechanism related somewhat to its ability to reduce oxidative stress and to maintain the activity of the antioxidant enzymes, as well as its ability to prevent the energy reduction in renal tissues [63]. In another study, Samarghandian et al. [64] indicated that the significant elevation in the levels of serum Cr, BUN, MDA, IL-6, IL-18, IL- $1 \beta$, and TNF- $\alpha$ and also the reduction of GSH, SOD, SOD, GPx, and IL-10 in the GM nephrotoxicity were improved by TQ $(10,20,30 \mathrm{mg} / \mathrm{kg})$, in a dose-dependent manner. These investigators proposed that TQ may improve acute renal failure by modulation of the oxidative stress and inflammatory responses.

\section{Methotrexate}

The study by El-Sheikh et al. [65] indicated that TQ treatment $(10 \mathrm{mg} / \mathrm{kg})$ concurrently with MTX in rats restored hepatorenal functions, as well as their normal histology. TQ also reversed oxidative and nitrosative stress, as well as inflammatory and apoptotic signs induced by MTX alone. This study proposed that TQ may be the useful adjuvant that gives hepatorenal protection to MTX toxicity through anti-inflammatory, antioxidant, antinitrosative, and antiapoptotic mechanisms.

\section{Acetaminophen}

Aycan et al. [66] studied the efficacy of TQ (10 mg/kg, i.p.) in acetaminophen (APAP)-induced renal toxicity in rat. The $\mathrm{Cr}$ and urea levels in the APAP + TQ treated 
group were importantly lower than in the APAP-treated group. In contrast to the group treated with APAP, the MDA levels and serum NO activity were significantly lower in the TQ + APAP group. Histopathological study showed lower tissue damage scores in the APAP + TQ group compared with the APAP group.

\section{Cyclosporine A}

Farag et al. [38] investigated the effects of chronic cyclosporine A (CsA) treatment and acute renal I/R on the liver and kidney in rats treated with TQ. TQ treatment $(10 \mathrm{mg} / \mathrm{kg}$ per day) decreased serum indicators back to control levels and improved CsA-induced renal and hepatic histopathological alterations. In renal and hepatic tissues, CsA and renal I/R induced considerable elevation of MDA levels with remarkable reduction in decreased GSH levels and SOD activities, as oxidative stress markers were neutralized by TQ therapy. This study showed that kidney and liver damage related to CsA or renal I/R can be significantly decreased by TQ.

\section{Lead}

Mabrouk and Ben Cheikh [67] investigated the possible beneficial effect of TQ on lead $(\mathrm{Pb})$-induced renal antioxidant defense system dysfunction in the rats. TQ treatment $(5 \mathrm{mg} / \mathrm{kg} /$ day, p.o.) improved the decreased SOD and GSH level, CAT, GPx, and glutathione reductase activities in the kidney tissue induced by $\mathrm{Pb}$ [67].

\section{Arsenic}

A study was carried out on the protective role of TQ against renal injury induced by arsenic in rats. Renal degenerative changes induced by arsenic were decreased by TQ (10 mg/kg, intragastric gavage for 15 days). Also, TQ ameliorated the increased MDA levels and increased the reduced SOD, CAT, and GSH-Px enzyme activities [68].

\section{Cadmium}

Erboga et al. [69] showed that TQ (50 mg/kg body weight) once a day orally in rats reduced the nephrotoxicity of cadmium (Cd) (1 mg/kg body weight). TQ preserved the normal histological architecture of the renal tissue. Furthermore, the immunohistochemical analysis indicated that TQ importantly reduced the Cd-induced overexpression of NF- $\mathrm{kB}$ in the kidney and also decreased apoptotic cells. TQ significantly repressed LPO and compensated dearth in the antioxidant defenses of the kidney. These results proposed that the nephroprotective potential of TQ in Cd toxicity may be related to its antioxidant and antiapoptotic effects, which could be helpful for obtaining optimum results in the Cd-induced nephrotoxicity [69].

\section{Mercuric Chloride}

Fouda et al. [70] investigated protective effects of TQ in mercuric chloride $\left(\mathrm{HgCl}_{2}\right)$-induced nephrotoxicity. Their results showed that the deterioration of antioxidant enzymes, increase in serum $\mathrm{Cr}$ and histological injury induced by $\mathrm{HgCl}_{2}$ were markedly ameliorated by TQ therapy $(10 \mathrm{mg} / \mathrm{kg} /$ day $)$. Additionally, apoptosis and proliferative reactions were decreased. The maximal protective effect proposed by TQ was 48 and $72 \mathrm{~h}$ after administration of $\mathrm{HgCl}_{2}$, when histological damage, renal cell apoptosis, and proliferative reactions reached their maximum. The findings showed the antioxidant effect of TQ.

\section{Kidney Calculi}

Kidney calculi are the term which is used to explain renal stones, which are formed in the urine that is made up of acid and mineral salts. They can block urine and cause renal infections, injury, and pain when they move around the body $[71,72]$. A study was done to investigate the effects of TQ on ethylene glycol-induced renal calculi in rats. Intraperitoneal injection of TQ $(5 \mathrm{mg} / \mathrm{kg})$ caused fewer deposits. Also, TQ ( $5 \mathrm{mg} / \mathrm{kg}$ or $10 \mathrm{mg} / \mathrm{kg}$, i.p.) importantly reduced the size and number of calcium oxalate sediments in the renal tubules [73]. Table 1 gives data on the protective effects of TQ on kidney diseases.

\section{TQ Toxicity}

Few studies reported TQ toxicity signs and symptoms in animal models. It was found that intraperitoneal injection of TQ caused peritonitis and abdominal muscle contractions and the oral administration of TQ caused dyspnea at different dose frequency exposure (acute, subacute, and subchronic) in rats and mice [74]. The maximum tolerated dose (MTD) of TQ, which is defined as the highest dose that is safe to administer to animal models in the absence of intolerable adverse effects, was determined in male and female Wistar rats [75]. The findings indicated that the MTD for intraperitoneal injection was $22.5 \mathrm{mg} / \mathrm{kg}$ in male rats and $15 \mathrm{mg} / \mathrm{kg}$ in females, whereas for oral administration it was $250 \mathrm{mg} / \mathrm{kg}$ in both male and female rats. Two rats died after administration of $500 \mathrm{mg} / \mathrm{kg}$ of TQ due to bowel obstruction. However, a possible mechanism of TQ toxicity was not fully understood [75]. 
Table 1. Protective effects of TQ on kidney diseases

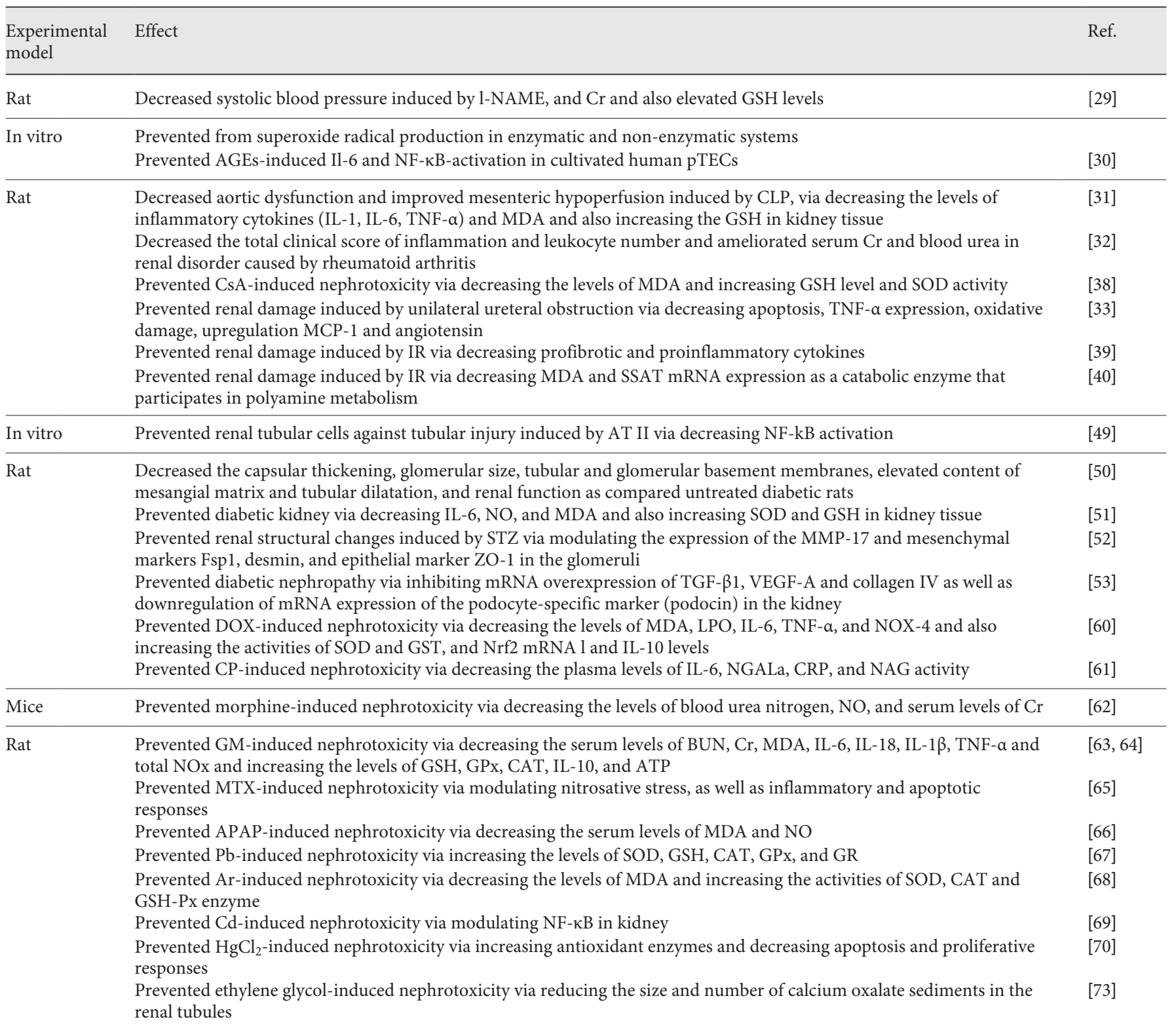

l-NAME, N(omega)-nitro-l-arginine methyl esters; GSH, glutathione peroxidase; AGEs, advanced glycation end products; pTECs, proximal tubular epithelial cells; IL, interleukin; CLP, cecal ligation and puncture; ALT, alanine aminotransferase; AST, aspartate aminotransferase; BUN, blood urea nitrogen; LDH, lactate dehydrogenase; $\mathrm{Cr}$, creatinine; MDA, malondialdehyde; TNF- $\alpha$, tumor necrosis factor; MCP-1, monocyte chemoattractant protein; UUO, unilateral ureteral obstruction; SOD, superoxide dismutase; GST, glutathione-S-transferase; I/R, ischemia-reperfusion; SSAT, spermidine/spermine N-1-acetyltransferase; IRI, ischemia-reperfusion injury; AT II, angiotensin II; pTECs, proximal tubular epithelial cells; SOD, superoxide dismutase; NO, nitric oxide; STZ, streptozotocin; TGF- $\beta 1$, transforming growth factor- $\beta 1$, VEGF-A, vascular endothelial growth factor-A; VEGF-A, vascular endothelial growth factorA; DOX, doxorubicin; LPO, lipid peroxidation; GST, glutathione-S-transferase; NOX-4, NADPH oxidase 4; Nrf2, nuclear factor erythroid 2-related factor 2; NGAL, neutrophil gelatinase-associated lipocalin; CRP, C-reactive protein; NAG, N-acetyl-b-D-glucosaminidase; GM, gentamicin; TBARS, thiobarbituric acid-reactive substances; NOx, nitrate/nitrite; GSH, glutathione peroxidase; GPx, glutathione peroxidase; CAT, catalase; ARF, acute renal failure; MTX,

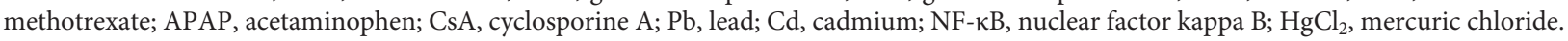




\section{Conclusions}

Scientific interest in medicinal plants and their ingredients has increased because of high efficiency of herbderived drugs, increasing interest in natural products. $N$. sativa seeds (Ranunculaceae family), have been used for thousands of years as a condiment and food preservative. TQ as the bioactive component of fugacious oil of black seed has indicated potent medicinal effects in traditional medicine. The studies provided clear documents that TQ has antioxidant effects via strengthening the oxidant scavenging system, and thus antitoxic properties. Also, it has shown potential anti-inflammatory effects $[76,77]$. This review indicated medicinal or protective features of TQ against inflammation and oxidative stress in renal disorders. TQ showed anti-inflammatory and antioxidant properties in animal and in vitro models of several renal diseases caused by inflammation and oxidative stress. TQ indicated anti-inflammatory effects through modulation of inflammatory molecules IL-1, IL-6, IL-18, IL-10, and TNF- $\alpha$, and NF- $\mathrm{\kappa B}$ activation. It also reduced the total clinical score of inflammation and leukocyte number. TQ decreased oxidative stress markers such as MDA and increased antioxidant content, including GSH, CAT, GST, and SOD, which have an important role in kidney disorders. It also ameliorated serum $\mathrm{Cr}$ and blood urea in renal disorder caused by rheumatoid arthritis or morphine in rats. In ethylene glycol-induced renal calculi, TQ led to lower deposits and decreased the size and number of calcium oxalate sediments in the renal tubules. Additionally, TQ improved the histopathological changes of the kidney induced by CLP, nephrotoxic agents, and diabetic nephropathies. Although experimental studies have shown the beneficial effects of TQ against renal diseases, well-designed clinical trials in humans are required to confirm these effects.

\section{Conflict of Interest Statement}

The authors declare that there is no conflict of interest regarding the publication of this article. There was no financial support or sponsorship for this work.

\section{References}

1 El-Tahir KE, Bakeet DM: The black seed $\mathrm{Ni}$ gella sativa linnaeus - a mine for multi cures: a plea for urgent clinical evaluation of its volatile oil. J Taibah Univ Sci 2006;1:1-9.

$\checkmark 2$ Aljabre SH, Alakloby OM, Randhawa MA: Dermatological effects of Nigella sativa. J Dermatol Dermatol Surg 2015;19:92-98.

3 Randhawa MA, Al-Ghamdi MS: A review of the pharmacotherapeutic effects of Nigella sativa. Pak J Med Res 2002;41:77-83.

4 Venkatachallam SK, Pattekhan H, Divakar S, Kadimi US: Chemical composition of Nigella sativa $\mathrm{L}$. seed extracts obtained by supercritical carbon dioxide. J Food Sci Technol 2010; 47:598-605.

5 Samarghandian S, Farkhondeh T, Samini F, Borji A: Protective effects of carvacrol against oxidative stress induced by chronic stress in rat's brain, liver, and kidney. Biochem Res Int 2016;2016:2645237.

6 Samarghandian S, Farkhondeh T, Samini F, Borji A: Protective effects of carvacrol against oxidative stress induced by chronic stress in rat's brain, liver, and kidney. Biochem Res Int 2016;2016:2645237.

7 Dehkordi FR, Kamkhah AF: Antihypertensive effect of Nigella sativa seed extract in patients with mild hypertension. Fundam Clin Pharmacol 2008;22:447-452.

-8 Samarghandian S, Borji A: Anticarcinogenic effect of saffron (Crocus sativus L.) and its ingredients. Pharmacognosy Res 2014;6:99_ 107.
-9 Chehl N, Chipitsyna G, Gong Q, Yeo CJ, Arafat HA: Anti-inflammatory effects of the $\mathrm{Ni}$ gella sativa seed extract, thymoquinone, in pancreatic cancer cells. HPB (Oxford) 2009; 11:373-381.

10 Samarghandian S, Azimi-Nezhad M, Farkhondeh $\mathrm{T}$ : Crocin attenuate tumor necrosis factor-alpha (TNF- $\alpha$ ) and interleukin-6 (IL6) in streptozotocin-induced diabetic rat aorta. Cytokine 2016;88:20-28.

11 Al-Ghamdi M: The anti-inflammatory, analgesic and antipyretic activity of Nigella sativa. J Ethnopharmacol 2001;176:45-48.

12 Samarghandian S, Azimi-Nezhad M, Farkhondeh T, Samini F: Anti-oxidative effects of curcumin on immobilization-induced oxidative stress in rat brain, liver and kidney. Biomed Pharmacother 2017;87:223-229.

-13 Islam S, Ahsan M, Hassan CM, Malek MA: Antifungal activities of the oils of Nigella sativa seeds. Pak J Pharm Sci 1989;2:25-28.

14 Morsi NM: Antimicrobial effect of crude extracts of Nigella sativa on multiple antibioticsresistant bacteria. Acta Microbiol Pol 1999; 49:63-74

15 Mahmoud SS, Torchilin VP: Hormetic/cytotoxic effects of Nigella sativa seed alcoholic and aqueous extracts on MCF-7 breast cancer cells alone or in combination with doxorubicin. Cell Biochem Biophys 2013;66:451-460.

$>16$ Raza M, Alghasham AA, Alorainy MS, ElHadiyah TM: Potentiation of valproate-induced anticonvulsant response by Nigella sa- tiva seed constituents: the role of GABA receptors. Int J Health Sci 2008;2:15.

-17 Kanter M, Coskun O, Budancamanak M: Hepatoprotective effects of Nigella sativa L and Urtica dioica $\mathrm{L}$ on lipid peroxidation, antioxidant enzyme systems and liver enzymes in carbontetrachloride-treated rats. World J Gastroenterol 2005;11:6684-6688.

18 Khazdair MR: The protective effects of Nigella sativa and its constituents on induced neurotoxicity. J Toxicol 2015;2015:841823.

19 Al Mofleh IA, Alhaider AA, Mossa JS, Al-Sohaibani MO, Al-Yahya MA, Rafatullah S, Shaik SA: Gastroprotective effect of an aqueous suspension of black cumin Nigella sativa on necrotizing agents-induced gastric injury in experimental animals. Saudi J Gastroenterol 2008; $14: 128$.

20 Nath KA, Norby SM: Reactive oxygen species and acute renal failure. Am J Med 2000;109: 665-678.

21 Vaziri ND, Ni Z, Oveisi F, Liang K, Pandian R: Enhanced nitric oxide inactivation and protein nitration by reactive oxygen species in renal insufficiency. Hypertension 2002;39:135-141.

22 Ha H, Hwang IA, Park JH, Lee HB: Role of reactive oxygen species in the pathogenesis of diabetic nephropathy. Diabetes Res Clin Pract 2008;82:S42-S45

23 Sedeek M, Nasrallah R, Touyz RM, Hébert $\mathrm{RL}$ : NADPH oxidases, reactive oxygen species, and the kidney: friend and foe. J Am Soc Nephrol 2013;24:1512-1518. 
24 Erkan N, Ayranci G, Ayranci E: Antioxidant activities of rosemary (Rosmarinus officinalis L.) extract, blackseed (Nigella sativa L.) essential oil, carnosic acid, rosmarinic acid and sesamol. Food Chem 2008;110:76-82.

-25 Shenawy EL, Nahla S, Soliman MF, Reyad SI: The effect of antioxidant properties of aqueous garlic extract and Nigella sativa as antischistosomiasis agents in mice. Rev Inst Med Trop Sao Paulo 2008;50:29-36.

26 Mariod AA, Ibrahim RM, Ismail M, Ismail N: Antioxidant activity and phenolic content of phenolic rich fractions obtained from black cumin (Nigella sativa) seedcake. Food Chem 2009;116:306-312.

-27 Chehl N, Chipitsyna G, Gong Q, Yeo CJ, Arafat HA: Anti-inflammatory effects of the $\mathrm{Ni}$ gella sativa seed extract, thymoquinone, in pancreatic cancer cells. HPB (Oxford) 2009; 11:373-381.

28 Umar S, Zargan J, Umar K, Ahmad S, Katiyar CK, Khan HA: Modulation of the oxidative stress and inflammatory cytokine response by thymoquinone in the collagen induced arthritis in Wistar rats. Chem Biol Interact 2012; 197:40-46.

29 Khattab MM, Nagi MN: Thymoquinone supplementation attenuates hypertension and renal damage in nitric oxide deficient hypertensive rats. Phytother Res 2007;21:410-414.

- 30 Sayed AA, Morcos M: Thymoquinone decreases AGE-induced NF- $\kappa B$ activation in proximal tubular epithelial cells. Phytother Res 2007;21:898-899.

- 31 Ozer EK, Goktas MT, Toker A, Pehlivan S, Bariskaner H, Ugurluoglu C, et al: Thymoquinone protects against the sepsis induced mortality, mesenteric hypoperfusion, aortic dysfunction and multiple organ damage in rats. Pharmacol Rep 2017;69:683-690.

- 32 Faisal R, Shinwari L, Jehangir T: Comparison of the therapeutic effects of thymoquinone and methotrexate on renal injury in pristane induced arthritis in rats. J Coll Physicians Surg Pak 2015;25:597-601.

- 33 Hosseinian S, Rad AK, Bideskan AE, Soukhtanloo M, Sadeghnia H, Shafei MN, et al: Thymoquinone ameliorates renal damage in unilateral ureteral obstruction in rats. Pharmacol Rep 2017;69:648-657.

-34 Wever KE, Warlé MC, Wagener FA, van der Hoorn JW, Masereeuw R, van der Vliet JA, Rongen GA: Remote ischaemic preconditioning by brief hind limb ischaemia protects against renal ischaemia-reperfusion injury: the role of adenosine. Nephrol Dial Transplant 2011;26:3108-3117.

35 Grynberg K, Ozols E, Mulley W, NikolicPaterson DJ, Ma FY: Conditional deletion of Jnk signalling in proximal tubular epithelial cells ameliorates renal ischaemia-reperfusion injury. Nephrology 2015;20:18.

- 36 Zhang J, Zou YR, Zhong X, Deng HD, Pu L, Peng K, et al: Erythropoietin pretreatment ameliorates renal ischaemia-reperfusion injury by activating PI3K/Akt signalling. Nephrology 2015;20:266-272.
37 Huang Q, Wang Q, Zhang S, Jiang S, Zhao L, $\mathrm{Yu}$ L, et al: Increased hydrogen peroxide impairs angiotensin II contractions of afferent arterioles in mice after renal ischaemia-reperfusion injury. Acta Physiol 2016;218:136145.

38 Farag MM, Ahmed GO, Shehata RR, Kazem $\mathrm{AH}$ : Thymoquinone improves the kidney and liver changes induced by chronic cyclosporine A treatment and acute renal ischaemia/ reperfusion in rats. J Pharm Pharmacol 2015; 67:731-739.

39 Hammad FT, Lubbad L: The effect of thymoquinone on the renal functions following ischemia-reperfusion injury in the rat. Int J Physiol Pathophysiol Pharmacol 2016;8:152.

40 Awad AS, Kamel R, Sherief MA: Effect of thymoquinone on hepatorenal dysfunction and alteration of CYP3A1 and spermidine/spermine $\mathrm{N}$-1-acetyl-transferase gene expression induced by renal ischaemia-reperfusion in rats. J Pharm Pharmacol 2011;63:1037-1042.

-41 Tervaert TW, Mooyaart AL, Amann K, Cohen AH, Cook HT, Drachenberg CB, et al: Pathologic classification of diabetic nephropathy. J Am Soc Nephrol 2010;21:556-563.

42 Navarro-González JF, Mora-Fernández C, De Fuentes MM, García-Pérez J: Inflammatory molecules and pathways in the pathogenesis of diabetic nephropathy. Nat Rev Nephrol 2011;7:327-340.

43 Fried LF, Emanuele N, Zhang JH, Brophy M, Conner TA, Duckworth W, et al: Combined angiotensin inhibition for the treatment of diabetic nephropathy. N Engl J Med 2013;369: 1892-1903.

44 Zhu W, Chen M, Shou Q, Li Y, Hu F: Biological activities of Chinese propolis and Brazilian propolis on streptozotocin-induced type $1 \mathrm{di}-$ abetes mellitus in rats. Evid Based Complement Alternat Med 2011;2011:468529.

45 Ozawa Y, Kurihara T, Sasaki M, Ban N, Yuki $\mathrm{K}$, Kubota S, et al: Neural degeneration in the retina of the streptozotocin-induced type 1 diabetes model. Exp Diabetes Res 2011;2011: 108328.

46 Luippold G, Klein T, Mark M, Grempler R: Empagliflozin. A novel potent and selective SGLT-2 inhibitor, improves glycaemic control alone and in combination with insulin in streptozotocin-induced diabetic rats, a model of type 1 diabetes mellitus. Diabetes Obes Metab 2012;14:601-607.

47 Abdelmeguid NE, Fakhoury R, Kamal SM, Al Wafai RJ: Effects of Nigella sativa and thymoquinone on biochemical and subcellular changes in pancreatic $\beta$-cells of streptozotocin-induced diabetic rats. J Diabetes 2010;2: 256-266.

48 Alimohammadi S, Hobbenaghi R, Javanbakht J, Kheradmand D, Mortezaee R, Tavakoli M, et al: Protective and antidiabetic effects of extract from Nigella sativa on blood glucose concentrations against streptozotocin (STZ)induced diabetic in rats: an experimental study with histopathological evaluation. Diagn Pathol 2013;8:137.
49 Sayed AA: Thymoquinone protects renal tubular cells against tubular injury. Cell Biochem Funct 2008;26:374-380.

50 Kanter M: Protective effects of thymoquinone on streptozotocin-induced diabetic nephropathy. J Mol Histol 2009;40:107-115.

51 Sayed AA: Thymoquinone and proanthocyanidin attenuation of diabetic nephropathy in rats. Eur Rev Med Pharmacol Sci 2012;16: 808-815.

52 Omran OM: Effects of thymoquinone on STZ-induced diabetic nephropathy: an immunohistochemical study. Ultrastruct Pathol 2014;38:26-33.

53 Al-Trad B, Al-Batayneh K, El-Metwally S, Alhazimi A, Ginawi I, Alaraj M, et al: Nigella sativa oil and thymoquinone ameliorate albuminuria and renal extracellular matrix accumulation in the experimental diabetic rats. Eur Rev Med Pharmacol Sci 2016;20:26802688.

54 Lopez-Novoa JM, Quiros Y, Vicente L, Morales AI, Lopez-Hernandez FJ: New insights into the mechanism of aminoglycoside nephrotoxicity: an integrative point of view. Kidney Int 2011;79:33-45.

55 Shahbazi F, Dashti-Khavidaki S, Khalili H, Lessan-Pezeshki M: Potential renoprotective effects of silymarin against nephrotoxic drugs: a review of literature. J Pharm Pharm Sci 2012;15:112-123.

56 McWilliam SJ, Antoine DJ, Sabbisetti V, Turner MA, Farragher T, Bonventre JV, et al: Mechanism-based urinary biomarkers to identify the potential for aminoglycoside-induced nephrotoxicity in premature neonates: a proof-of-concept study. PLoS One 2012; 7:e43809.

57 Perazella MA, Moeckel GW: Nephrotoxicity from chemotherapeutic agents: clinical manifestations, pathobiology, and prevention/ therapy. Semin Nephrol 2010;30:570-581.

58 Maru S, Abe T, Shinohara N, Sazawa A, Maruyama S, Harabayashi T, et al: Influence of baseline renal function and dose reduction of nephrotoxic chemotherapeutic agents on the outcome of metastatic urothelial carcinoma: a retrospective study. Int J Urol 2012;19: $110-116$.

59 Cascella M, Palma G, Barbieri A, Bimonte S, Amruthraj NJ, Muzio MR, et al: Role of Nigella sativa and its constituent thymoquinone on chemotherapy-induced nephrotoxicity: evidences from experimental animal studies. Nutrients 2017;9:625.

60 Elsherbiny NM, El-Sherbiny M: Thymoquinone attenuates doxorubicin-induced nephrotoxicity in rats: role of Nrf2 and NOX4. Chem Biol Interact 2014;223:102-108.

61 Ali BH, Al Za'abi M, Shalaby A, Manoj P, Waly MI, Yasin J, et al: The effect of thymoquinone treatment on the combined renal and pulmonary toxicity of cisplatin and diesel exhaust particles. Exp Biol Med 2015;240: 1698-1707. 
62 Jalili C, Salahshoor MR, Hoseini M, Roshankhah S, Sohrabi M, Shabanizadeh A: Protective effect of thymoquinone against morphine injuries to kidneys of mice. Iran J Kidney Dis 2017;11:142-150.

63 Sayed-Ahmed MM, Nagi MN: Thymoquinone supplementation prevents the development of gentamicin-induced acute renal toxicity in rats. Clin Exp Pharmacol Physiol 2007; 34:399-405.

64 Samarghandian S, Azimi-Nezhad M, Mehrad-Majd H, Mirhafez SR: Thymoquinone ameliorates acute renal failure in gentamicintreated adult male rats. Pharmacology 2015; 96:112-117.

-65 El-Sheikh AA, Morsy MA, Abdalla AM, Hamouda AH, Alhaider IA: Mechanisms of thymoquinone hepatorenal protection in methotrexate-induced toxicity in rats. Mediators Inflamm 2015;2015:859383.

66 Aycan İÖ, Tokgöz O, Tüfek A, Alabalık U, Evliyaoğlu O, Turgut $\mathrm{H}$, et al: The use of thymoquinone in nephrotoxicity related to acetaminophen. Int J Surg 2015;13:33-37.
67 Mabrouk A, Cheikh HB: Thymoquinone ameliorates lead-induced suppression of the antioxidant system in rat kidneys. Libyan J Med 2016;11:310-318.

68 Sener U, Uygur R, Aktas C, Uygur E, Erboga M, Balkas G, et al: Protective effects of thymoquinone against apoptosis and oxidative stress by arsenic in rat kidney. Ren Fail 2016; 38:117-123.

69 Erboga M, Kanter M, Aktas C, Sener U, Erboga ZF, Donmez YB, et al: Thymoquinone ameliorates cadmium-induced nephrotoxicity, apoptosis, and oxidative stress in rats is based on its anti-apoptotic and anti-oxidant properties. Biol Trace Elem Res 2016;170: 165-172.

70 Fouda AM, Daba MH, Dahab GM, Sharaf el-Din OA: Thymoquinone ameliorates renal oxidative damage and proliferative re sponse induced by mercuric chloride in rats. Basic Clin Pharmacol Toxicol 2008;103: 109-118.

71 Wu P, Wang L, Wang K: Supine versus prone position in percutaneous nephrolithotomy for kidney calculi: a meta-analysis. Int J Biochem Cell Biol 2011;43:67-77.
72 Okhunov Z, Friedlander JI, George AK, Duty BD, Moreira DM, Srinivasan AK, et al: STONE nephrolithometry: novel surgical classification system for kidney calculi. Urology 2013;81:1154-1160.

73 Hadjzadeh MA, Mohammadian N, Rahmani Z, Behnam Rassouli F: Effect of thymoquinone on ethylene glycol-induced kidney calculi in rats. Urol J 2008;5:149-155.

74 Abukhader MM: The effect of route of administration in thymoquinone toxicity in male and female rats. Indian J Pharm Sci 2012;74: 195-200.

75 Al-Ali A, Alkhawajah AA, Randhawa MA, Shaikh NA: Oral and intraperitoneal LD50 of thymoquinone, an active principle of Nigella sativa, in mice and rats. J Ayub Med Coll Abbottabad 2008;20:25-27.

76 Gali-Muhtasib H, Roessner A, SchneiderStock R: Thymoquinone: a promising anticancer drug from natural sources. Int J Biochem Cell Biol 2006;38:1249-1253.

77 Ramadan MF: Nutritional value, functional properties and nutraceutical applications of black cumin (Nigella sativa L.): an overview. J Food Sci Technol 2007;42:1208-1218. 